\title{
Bridge Management Strategy Based on Extreme User Costs for Bridge Network Condition
}

\author{
Ladislaus Lwambuka $^{1}$ and Primus V. Mtenga ${ }^{2}$ \\ ${ }^{1}$ University of Dar es Salaam, P.O. Box 35131, Dar es Salaam, Tanzania \\ ${ }^{2}$ Florida A\&M University, Florida State University, 2525 Potsdamer Street, Tallahassee, FL 32310, USA \\ Correspondence should be addressed to Primus V. Mtenga; mtenga@eng.fsu.edu
}

Received 5 July 2014; Revised 8 September 2014; Accepted 23 September 2014; Published 14 October 2014

Academic Editor: Andreas Kappos

Copyright ( 2014 L. Lwambuka and P. V. Mtenga. This is an open access article distributed under the Creative Commons Attribution License, which permits unrestricted use, distribution, and reproduction in any medium, provided the original work is properly cited.

\begin{abstract}
This paper presents a practical approach for prioritization of bridge maintenance within a given bridge network. The maintenance prioritization is formulated as a multiobjective optimization problem where the simultaneous satisfaction of several conflicting objectives includes minimization of maintenance costs, maximization of bridge deck condition, and minimization of traffic disruption and associated user costs. The prevalence of user cost during maintenance period is twofold; the first case refers to the period of dry season where normally the traffic flow is diverted to alternative routes usually resurfaced to regain traffic access. The second prevalence refers to the absence of alternative routes which is often the case in the least developed countries; in this case the user cost referred to results from the waiting time while the traffic flow is put on hold awaiting accomplishment of the maintenance activity. This paper deals with the second scenario of traffic closure in the absence of alternative diversion routes which in essence results in extreme user cost. The paper shows that the multiobjective optimization approach remains valid for extreme cases of user costs in the absence of detour roads as often is the scenario in countries with extreme poor road infrastructure.
\end{abstract}

\section{Bridge Maintenance Management Problem}

The Tanzania Roads Agency (TANROADS) has developed a bridge maintenance management system called TANBRIDGEMAN, which in its current version of 2002 has the following features:

(i) annual bridge inventory data;

(ii) bridge inspection data (which incorporates condition rating of critical components of the bridge and recommendation on remedial measures);

(iii) maintenance cost computations.

TANBRIDGEMAN however prioritizes the maintenance on basis of the condition rating and maintenance cost only. The discussion at hand is to expand the maintenance prioritization by incorporating user cost.

In any facility management scenario, such as in bridge management system, the issue becomes how to prioritize bridge maintenance by satisfying three conflicting objectives simultaneously. The three types of targeted objectivesoriented prioritization are the following:

(1) damage condition rating-based prioritization: the projects will be ranked in terms of condition rating; that is, the project with the highest condition rating (the most damaged condition state) will be given first priority;

(2) maintenance cost-based prioritization: the projects will be ranked in terms of maintenance cost; that is, the projects with the lowest maintenance cost will be given first priority;

(3) user cost-based prioritization: the projects will be ranked in terms of user costs; that is, the projects with the highest user cost will be given first priority. 
Thus, these three major objectives in a BMS are conflicting (competing) with each other so that in this bridge management problem it is necessary to find an "ideal solution" that is considered to be a satisfactory trade-off between the three conflicting objectives.

This ideal solution is defined as the solution that yields minimum (or maximum) values for all criteria in the conflicting objectives. In other words, we need to develop a multiobjective optimality index. This index can then be used as an effective optimality criterion for the prioritization of deteriorated bridge component for maintenance [1].

\section{Bridge Performance Model}

Condition assessment of bridge structures is a key in detecting the degree of deterioration with respect to the bridge in its original conditions.

We need to predict the rate of deterioration (transition) of a bridge component within the bridge network.

From the historical data obtained from the regular condition rating of a bridge component, prediction of the bridge condition index (BCI) can be computed using the transition probability [2-4], which is generated from the data collected during bridge inspections and is presented in form of a damage state matrix/vector as follows:

$$
\mathbf{p}_{\mathbf{t}}=\mathbf{p}_{\mathbf{o}} P_{i}^{t}
$$

where the vector $\mathbf{p}_{\mathbf{o}}$ defines the initial state damage $\mathbf{p}_{\mathbf{o}}=$ [ $\left.p_{o}(i)\right] i=1, b$, where $p_{o}(i)$ is the probability of being in state $i$ at time $t=0$. Usually, the damage rating is $i=1-9$, whereby if a bridge component is categorized as state number 1 it means that the component is in its pristine state (undamaged condition) while condition state number 9 refers to the most damaged condition.

$P_{i}^{t}$ is the probability of the bridge component being in state $i$ after time interval $t$ and is defined as

$$
P_{i}^{t}=\left[p_{t}(i)\right] \quad i=1, b .
$$

The expected condition index $f$ for the bridge component $x$ is determined from the calculated transient probabilities using the following equation:

$$
\begin{aligned}
& f(x) \\
& =\left(1 P_{1}^{t}+2 P_{2}^{t}+3 P_{3}^{t}+4 P_{4}^{t}+5 P_{5}^{t}+6 P_{6}^{t}+7 P_{7}^{t}+8 P_{8}^{t}+9 P_{9}^{t}\right),
\end{aligned}
$$

where $t$ is the time in years.

\section{Maximization of Condition Rating}

In many bridge management systems (BMS) the condition state of a specific bridge element, for this case the bridge deck, is evaluated and assigned a condition number. To this effect the inspector rates the condition of the bridge deck and assigns condition ratings of the deck. This condition rating consists of mapping of the level of the observed damage in the structure during visual inspections and nondestructive evaluation (or predicted using empirical or statistical methods) onto a discrete 1 to 9 rating scale. The condition state variation with time is then analyzed on basis of the historical condition data, usually on the basis of a discrete-time discrete-state assumption, using the Markov chains models [5, 6]. This analysis leads to the establishment of transition probabilities which can be used to predict future bridge conditions [7].

The objective of condition rating, therefore, is targeting the maximization of the condition and performance of a bridge component.

\section{Minimization of Maintenance Costs}

We need to establish the maintenance cost of each project (individual bridge component within the network), which is dependent on the level of deterioration at the time the maintenance operation is conducted.

From experience it is possible to predict the maintenance costs to raise the condition index of a bridge component condition from $j$ to $i(i>j)$. To this effect the projects are ranked in terms of increasing costs for maintenance, whereby the higher the condition index predicted the higher the expected maintenance costs.

The objective is to prioritize the project with the least maintenance cost.

\section{Minimization of User Costs}

In developed countries the incorporation of user costs in the Euclidean model is usually based on the additional costs incurred by traffic using the alternative diversion routes as a result of bridge closure until the accomplishment of the maintenance activity. For most developing countries, however, this option of diversion routes is often not available so that the user cost in question refers to the social cost incurred while traffic flow is put on hold awaiting accomplishment of the maintenance activity.

The user cost is assumed to represent the sum of all costs incurred by the users during the maintenance activity and to depend primarily on the duration of the maintenance activity [1].

The objective is to prioritize the project with the highest user costs.

\section{Multiobjective Optimization Problem}

The concept of maintenance optimization problem is for the bridge owner or bridge manager seeking to satisfy simultaneously several objectives, such as improvement of bridge safety, minimization of maintenance costs, and minimization of user costs. The solution of this maintenance management problem can be obtained using the techniques of multicriteria or multiobjective optimization. However, the notion of optimality is not obvious because of the presence of multiple, incommensurable, and conflicting objectives, so that there is no single optimal solution that yields simultaneously the desired minimum (or maximum) for all objective functions. To this effect a Pareto optimality concept was introduced as 
a solution to multiobjective optimization problems $[8,9]$, which targets obtaining a maintenance strategy $x^{*}$ as the Pareto optimum. Mathematically, the multiobjective maintenance optimization can be stated as follows.

Find

$$
x^{*}=\left[x_{1}^{*}, x_{2}^{*}, \ldots, x_{n}^{*}\right]=\text { optimum }
$$

such that

$$
\begin{gathered}
f(x)=\left[f_{1}(x), f_{2}(x), \ldots, f_{n}(x)\right]=\text { minimum } \quad x \in \Omega, \\
\sum_{j=1}^{n} C_{m, t}\left(x_{j}\right) \leq C_{\text {max }}, \\
\Omega=\left\{x \in N: \mathrm{CR}(x) \geq \mathrm{CR}_{\text {threshold }}\right\},
\end{gathered}
$$

where $x^{*}$ is the vector of optimum solutions, $N$ is the entire set of bridge components, $f$ is the vector of optimum objectives, $C_{m, t}$ is the maintenance cost of project $x_{j}^{*}$ at time $t, C_{\max }$ is the available budget, $\mathrm{CR}$ is the condition rating, and $\Omega$ is the subset of deficient bridge components.

\section{Decision-Making under Multiple and Conflicting Objectives}

Because of the complexity involved in getting the true optima, compromise solution has been suggested in the literature (e.g., [10-12], etc.) using a "satisficing" solution that achieves the best compromise between all competing objectives. It is the ideal solution that yields minimum (or maximum) values for all criteria.

Determination of the "satisficing" solution is attained by minimizing the distance from the set of Pareto optima to the so-called "ideal solution."

A multiobjective index (MOI) has been proposed [8]. The MOI is defined as the value of the weighted and normalized deviation from the ideal solution $f^{*}$ measured by the family of $L_{p}$ metrics:

$$
\operatorname{MOI}_{p}(x)=\left[\sum_{j=1}^{m} w_{j}^{p}\left(\left|\frac{f_{j}(x)-\min f_{j}(x)}{\max f_{j}(x)-\min f_{j}(x)}\right|\right)^{p}\right]^{1 / p},
$$

where $w$ values depend on the risk tolerance of the decision maker in dealing with the objective. The choice of $p$ indicates the importance given to different deviations from the ideal solution.

\section{The Case of Extreme User Costs}

For least developed countries roadway networks are very rudimentary. Taking the case of Tanzania as an example, we find that because of the absence of functioning railway line the roadway network is extremely wanting. Tanzania's roadway network serves Tanzania as well as the neighboring countries which include the eastern parts of the Democratic Republic of the Congo (DRC), Zambia, Malawi, Burundi,

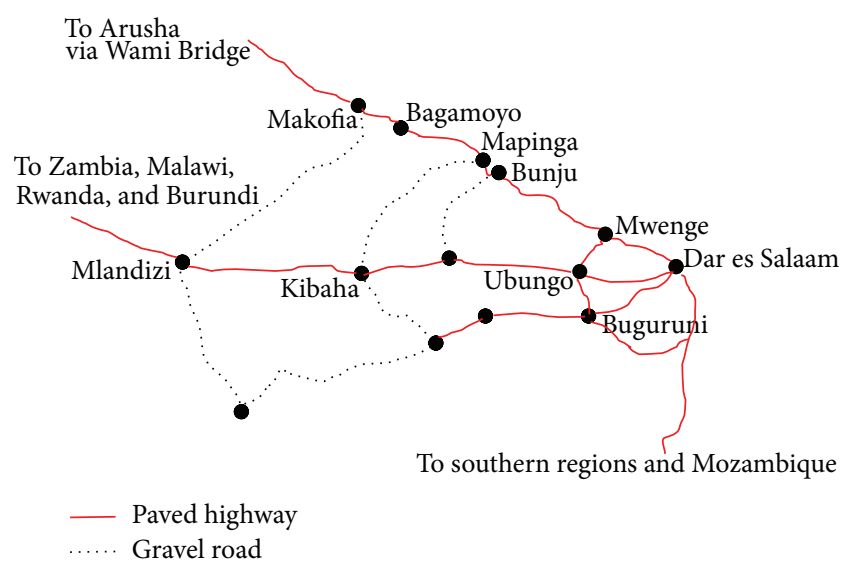

FIGURE 1: Sketch of highway network on the Dar es Salaam to Mlandizi corridor. The sketch of the Dar es Salaam to Mlandizi transportation corridor.

Rwanda, and Uganda. The Tanzanian road network is such that if a closure of an artery occurs between Kibaha and Mlandizi on the Tanzania-Zambia highway in the rainy season, detours of such a closure, which is normally very long, become impassable resulting in extreme user cost.

As opposed to deterioration of a patch on the paved surface (pot holes, etc.), a deteriorated bridge will necessitate an outright closure of a network artery and, as a result, it is important to develop a rational method of allocating resources to bridge maintenance at the network level, that is, taking into consideration the condition of the bridge and the criticality of the artery in the roadway network served by the particular bridge for prioritization through index processing. Shown in Figure 1 is a schematic of the network of roads for traffic getting out of Dar es Salaam. As it can be observed in this sketch the alternative routes are unpaved gravel roads (dashed lines) with bridges that are not rated for buses and heavy trucks ferrying cargo to the neighboring countries.

In the study reported in this paper the conditions of bridge decks between Dar es Salaam and Mlandizi were rated based on the model discussed above. Maintenance costs were determined based on historical data obtained from the Tanzania Roads Agency (TANROADS).

For this study extreme user cost is estimated as shown in Figure 2 by considering the fact that there is no diversion route during the maintenance process taking into account (i) the waiting time for road users while the traffic flow is put on hold awaiting completion of the maintenance activity and (ii) paralyzed economic activities as a result of road closure.

The duration of maintenance based on the BCI has been established from the TANBRIDGEMAN.

Presented in Table 1 is data for the bridges considered in this study showing the values of the bridge condition index, such as the BR-5 which is displayed in Figure 3, maintenance, and user cost due to bridge closure during the implementation of the maintenance activity.

Presented in Figure 4 are the normalized values (normalized with respect to the maximum value).

The conflicting nature of the objective functions is evident in Table 1 and Figure 4 because the project with the highest 
TABLE 1: Competing objective values for the road section Dar es Salaam-Mlandizi.

\begin{tabular}{lccccc}
\hline Project & BCI & $\begin{array}{c}\text { Duration of maintenance } \\
(\mathrm{hrs})\end{array}$ & Maintenance cost (\$ '000) & $\begin{array}{c}\text { Stranded vehicles } \\
\text { (cars/heavy vehicles) }\end{array}$ & User cost (\$ 000) \\
\hline BR-1 & 2 & 2.0 & 40 & $50 / 25$ & 50 \\
BR-2 & 4 & 4.0 & 60 & $250 / 100$ & 260 \\
BR-3 & 7 & 16.0 & 160 & $800 / 480$ & 1100 \\
BR-4 & 3 & 11.4 & 140 & $560 / 380$ & 860 \\
BR-5 & 4 & 3.6 & 130 & $250 / 100$ & 260 \\
BR-6 & 5 & 12.0 & 170 & $600 / 380$ & 900 \\
BR-7 & 2 & 3.0 & 70 & $120 / 50$ & $900 / 400$ \\
BR-8 & 6 & 14.0 & 180 & $600 / 390$ & 1220 \\
BR-9 & 5 & 12.4 & 190 & & 580 \\
\hline
\end{tabular}

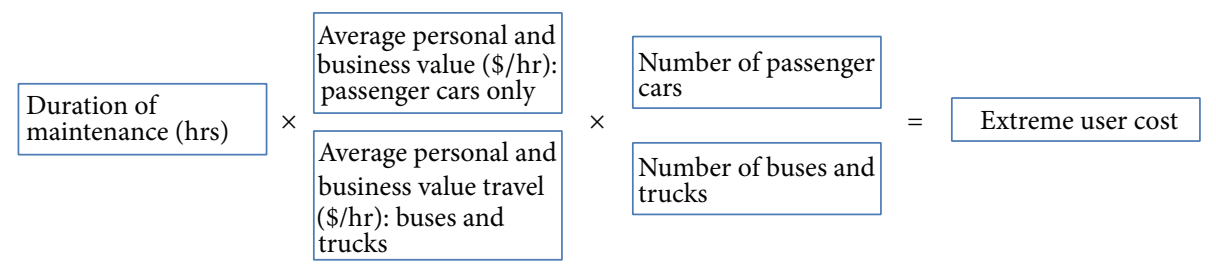

FIgURE 2: Computation of extreme user cost.
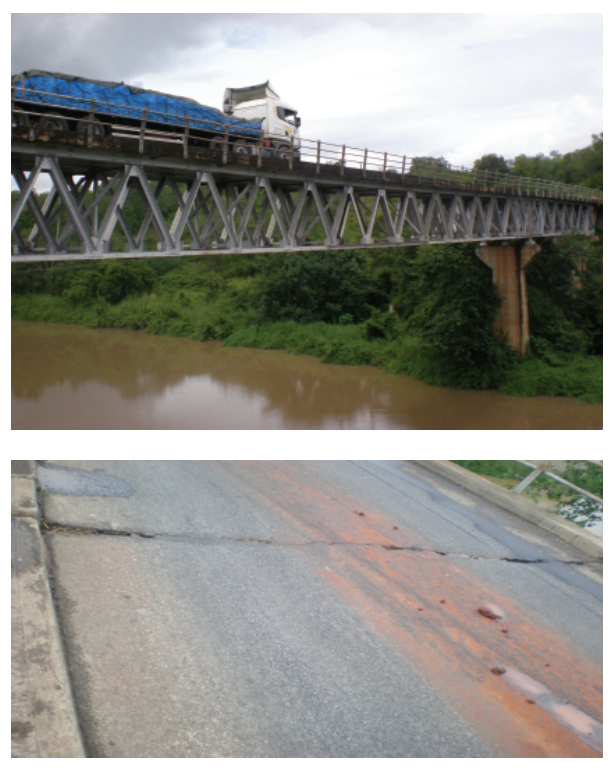

Figure 3: The Project BR-5 and part of the deterioration of the bridge deck.

urgency in terms of condition index (project number 3) is not the same neither in terms of maintenance cost (project number 9) nor in terms of user cost (project number 8 ).

\section{Decision Making under Conflicting Objectives}

In consideration of excessive user costs the decision for maintenance under scenario 1 is only sought for bridges number $1,2,5$, and 7 , whereas the remaining prioritization is considered for scenario 2 .
Using the minimum MOI criterion of (6), the "satisfying" solution is found to be project number 7 as the one to be accorded top priority as reflected in Figure 5.

\section{Conclusion}

This paper provides a feasible approach in bridge deck maintenance optimization for accommodating cases of extreme user costs which is prevalent in areas with extreme poor road infrastructure. The maintenance prioritization based on the simultaneous satisfaction of several conflicting objectives 


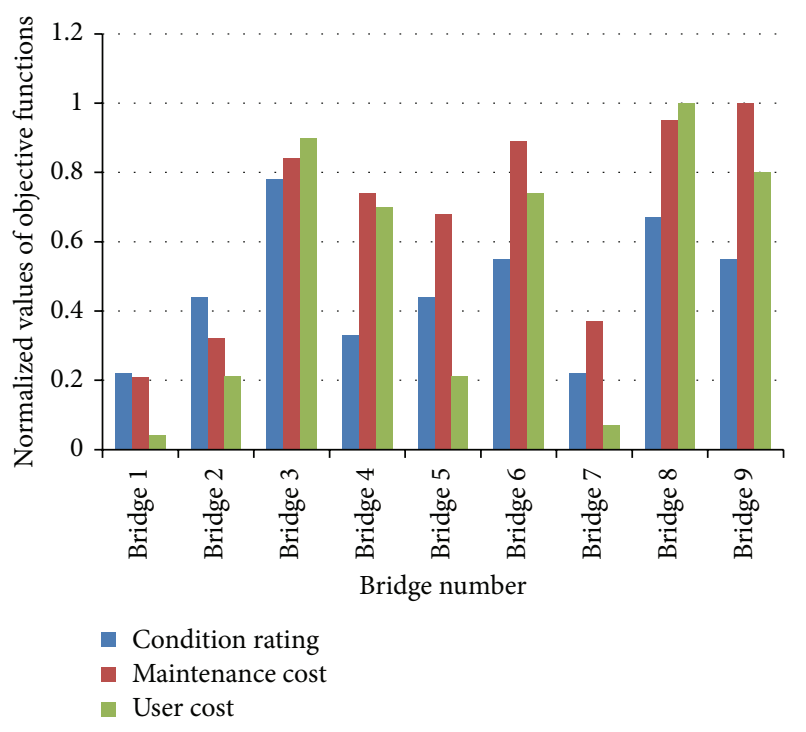

FIGURE 4: Normalized values of objective functions for bridge maintenance.

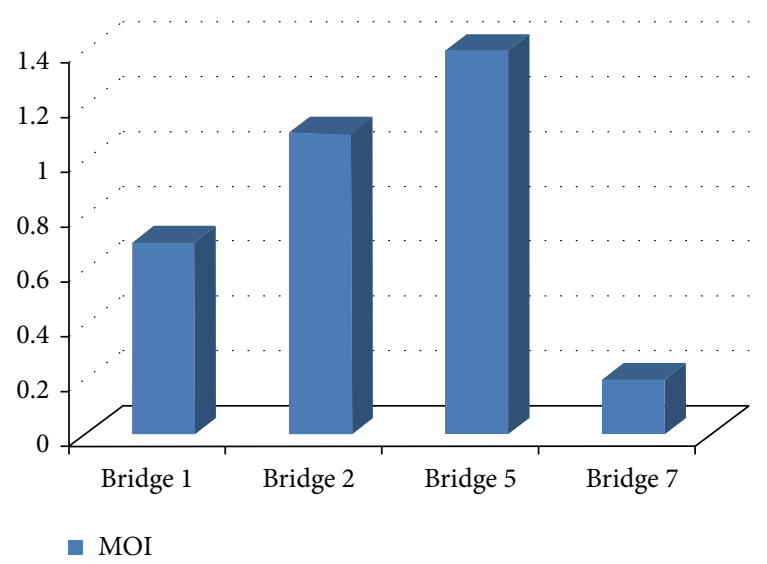

FIGURE 5: Multiobjective-based maintenance prioritization.

is not limited to reasonable user costs but can also include extreme cases for the scenario of detour roads not being feasible. The multiobjective optimization approach remains valid for application on cases of extreme user costs as a result of traffic flow put on hold to await accomplishment of maintenance activity.

\section{Conflict of Interests}

The authors declare that there is no conflict of interests regarding the publication of this paper.

\section{References}

[1] Z. Lounis, "Risk-based maintenance optimization for aging bridge decks," Advances in Engineering Structures, Mechanics \& Construction. Solid Mechanics and Its Applications, vol. 140, Part 7, pp. 723-734, 2006.
[2] J. L. Bogdanoff, "A new cumulative damage model-Part 1," Transactions ASME, Journal of Applied Mechanics, vol. 45, no. 2, pp. 246-250, 1978.

[3] P. D. Thompson, J. O. Sobanjo, and R. Kerr, "Florida DOT project-level bridge management models," Journal of Bridge Engineering, vol. 8, no. 6, pp. 345-352, 2003.

[4] J. Sobanjo, P. Mtenga, and M. Rambo-Roddenberry, "Reliability-based modeling of bridge deterioration hazards," Journal of Bridge Engineering, vol. 15, no. 6, pp. 671-683, 2010.

[5] P. D. Thompson and M. B. Johnson, "Markovian bridge deterioration: developing models from historical data," Structures and Infrastructure Engineering, vol. 1, no. 1, pp. 85-91, 2005.

[6] G. Morcous, "Performance prediction of bridge deck systems using markov chains," Journal of Performance of Constructed Facilities, vol. 20, no. 2, pp. 146-155, 2006.

[7] J. O. Sobanjo, "State transition probabilities in bridge deterioration based on weibull sojourn times," Structure and Infrastructure Engineering, vol. 7, no. 10, pp. 747-764, 2011.

[8] J. Koski, "Multi-objective optimization in structural design," in New Directions in Optimum Structural Design, pp. 484-503, John Wiley \& Sons, New York, NY, USA, 1984.

[9] L. Duckstein, "Multi-objective optimization in structural design: the model choice problem," in New Directions in Optimum Structural Design, pp. 459-481, John Wiley \& Sons, New York, NY, USA, 1984.

[10] Y. Robert-Nicoud, B. Raphael, O. Burdet, and I. F. C. Smith, "Model identification of bridges using measurement data," Computer-Aided Civil and Infrastructure Engineering, vol. 20, no. 2, pp. 118-131, 2005.

[11] S. Ravindran, P. Kripakaran, and I. F. C. Smith, "Evaluation reliability of multiple-model system identification," in Proceedings of the 14th European Group for Intelligent Computing in Engineering Workshop (EG-ICE '07), pp. 643-652, Maribor, Slovenia, June 2007.

[12] R. Hadidi and N. Gucunski, "Probabilistic approach to the solution of inverse problems in civil engineering," Journal of Computing in Civil Engineering, vol. 22, no. 6, pp. 338-347, 2008. 

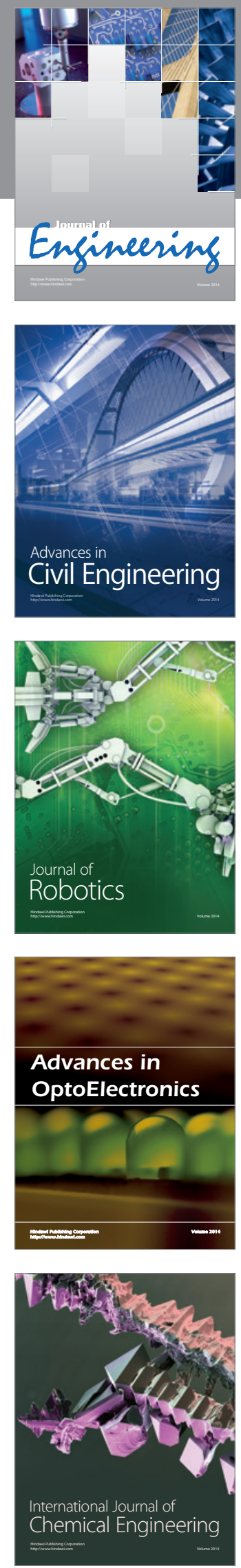

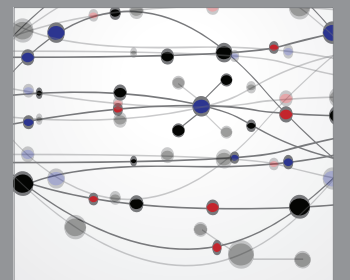

The Scientific World Journal
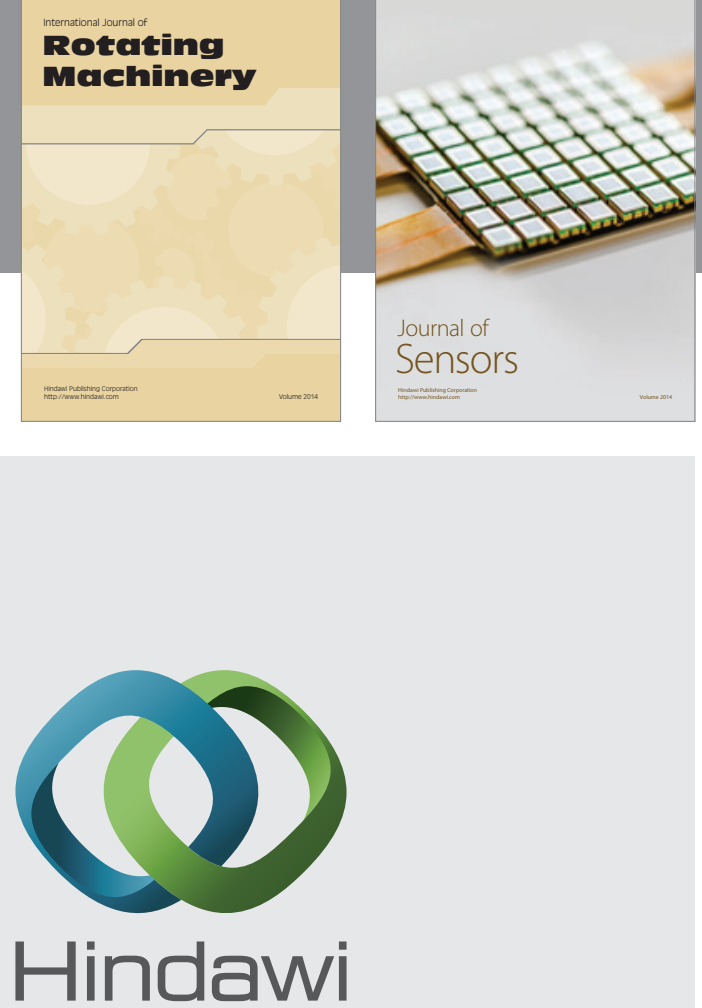

Submit your manuscripts at http://www.hindawi.com
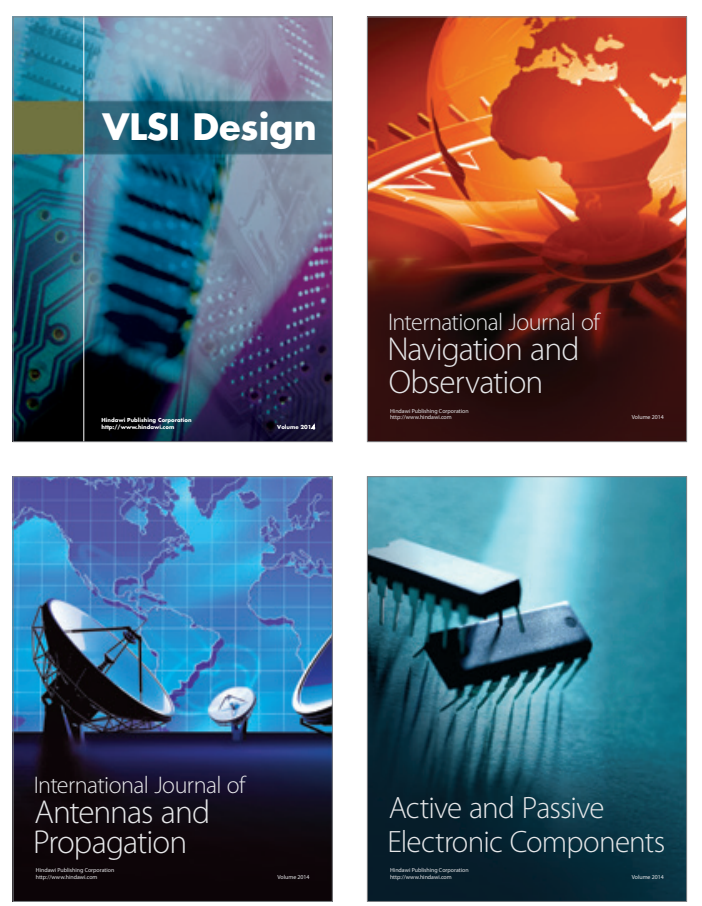
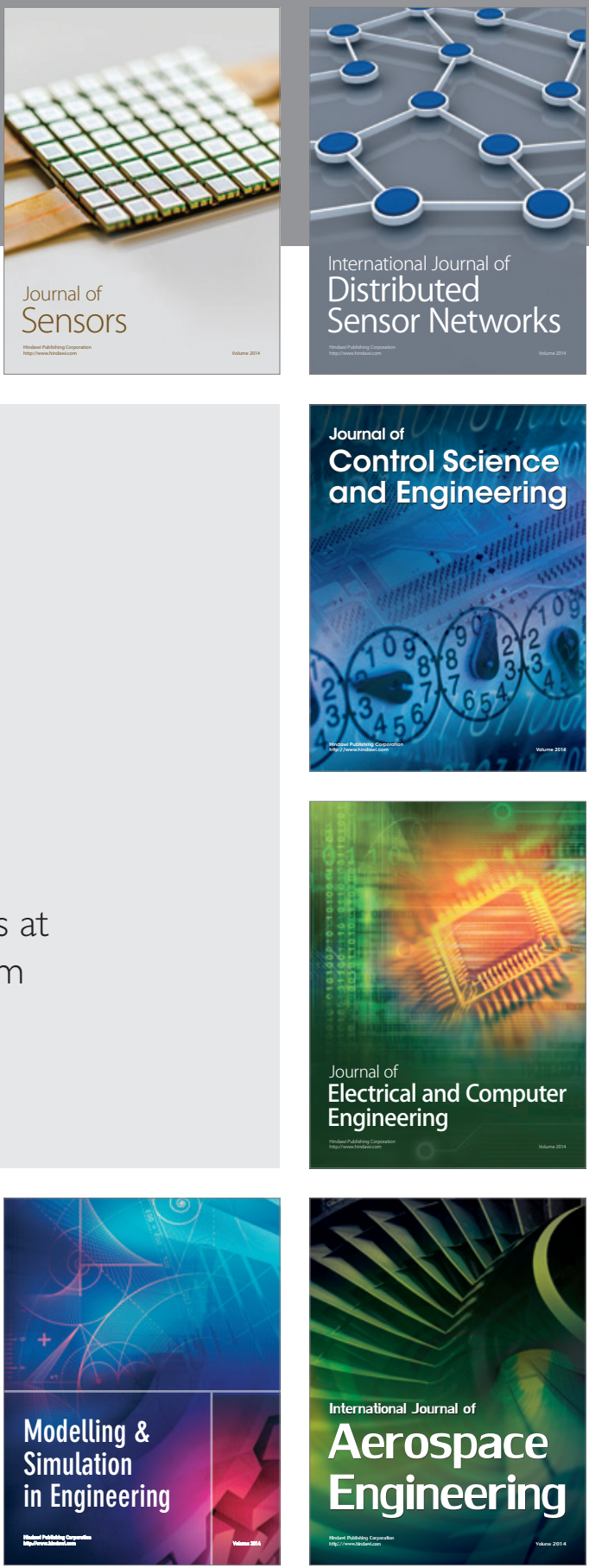

Journal of

Control Science

and Engineering
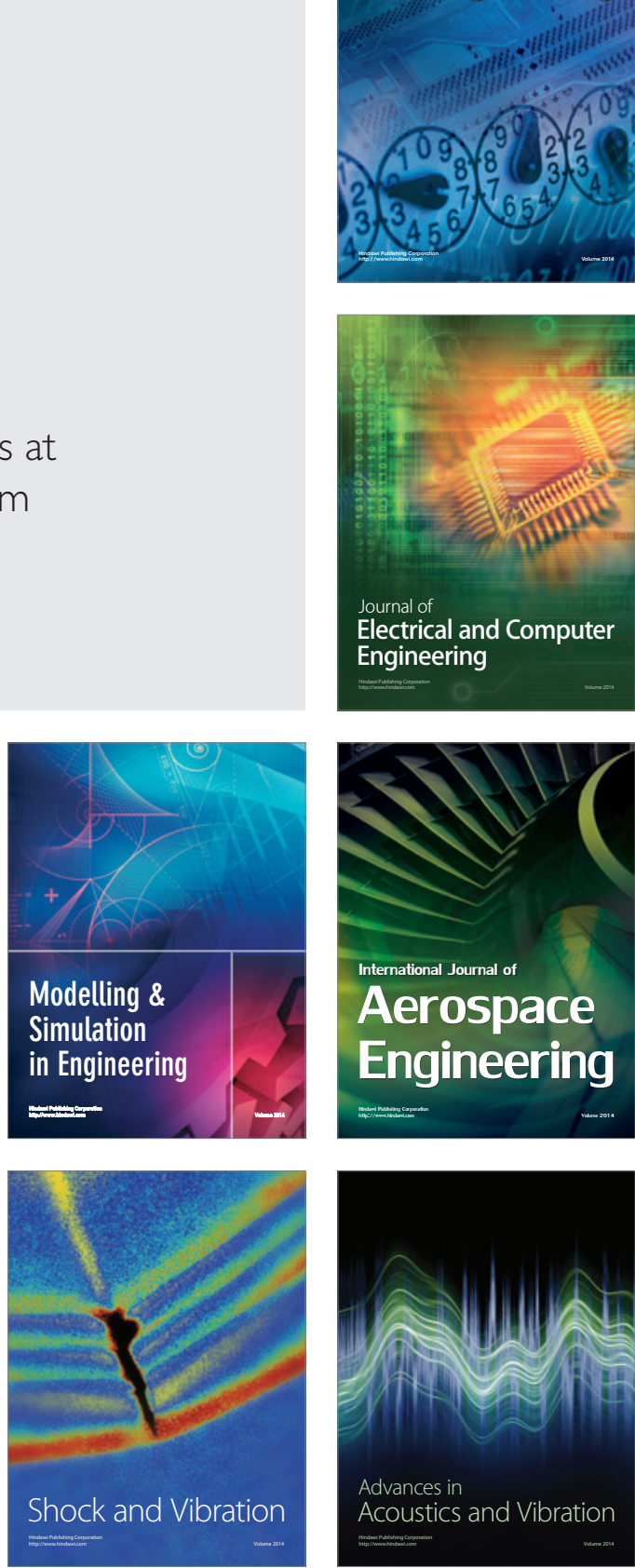